\title{
Evaluation of Samarium Doped Hydroxyapatite, Ceramics for Medical Application: Antimicrobial Activity
}

\author{
C. S. Ciobanu, ${ }^{1,2}$ S. L. Iconaru, ${ }^{1}$ C. L. Popa, ${ }^{1}$ M. Motelica-Heino, ${ }^{3}$ and D. Predoi ${ }^{1}$ \\ ${ }^{1}$ National Institute for Materials Physics, P.O. Box MG 07, Bucharest, 077125 Magurele, Romania \\ ${ }^{2}$ Department of Science and Engineering of Oxide Materials and Nanomaterials, Faculty of Applied Chemistry and Materials Science, \\ University POLITEHNICA of Bucharest, 1-7 Polizu Street, P.O. Box 12-134, 011061 Bucharest, Romania \\ ${ }^{3}$ ISTO, UMR 7327, CNRS-Université d'Orléans, 1 A rue de la Férollerie, 45071 Orléans Cedex 2, France
}

Correspondence should be addressed to D. Predoi; dpredoi@gmail.com

Received 25 September 2014; Revised 20 December 2014; Accepted 21 December 2014

Academic Editor: Xiaoming Li

Copyright (C) 2015 C. S. Ciobanu et al. This is an open access article distributed under the Creative Commons Attribution License, which permits unrestricted use, distribution, and reproduction in any medium, provided the original work is properly cited.

\begin{abstract}
Samarium doped hydroxyapatite (Sm:HAp), $\mathrm{Ca}_{10-x} \mathrm{Sm}_{x}\left(\mathrm{PO}_{4}\right)_{6}(\mathrm{OH})_{2}$ (HAp), bionanoparticles with different $x_{\mathrm{Sm}}$ have been successfully synthesized by coprecipitation method. Detailed characterization of samarium doped hydroxyapatite nanoparticles (Sm:HAp-NPs) was carried out using X-ray diffraction (XRD), scanning electron microscopy (SEM), transmission electron microscopy (TEM), and Fourier transform infrared spectroscopy (FTIR). The biocompatibility of samarium doped hydroxyapatite was assessed by cell viability. The antibacterial activity of the Sm:HAp-NPs was tested against Gram-negative bacteria (Pseudomonas aeruginosa and Escherichia coli) and Gram-positive bacteria (Enterococcus faecalis and Staphylococcus aureus). A linear increase of antimicrobial activity of $P$. aeruginosa has been observed when concentrations of Sm:HAp-NPs in the samples with $x_{\mathrm{Sm}}=0.02$ were higher than $0.125 \mathrm{mg} / \mathrm{mL}$. For Sm:HAp-NPs with $x_{\mathrm{Sm}}=0.05$ a significant increase of antibacterial activity on $E$. coli was observed in the range $0.5-1 \mathrm{mg} / \mathrm{mL}$. For low concentrations of Sm:HAp-NPs $\left(x_{\mathrm{Sm}}=0.05\right)$ from 0.031 to $0.125 \mathrm{mg} / \mathrm{mL}$ a high antibacterial activity on Enterococcus faecalis has been noticed. A growth of the inhibitory effect on $S$. aureus was observed for all concentrations of Sm:HAp-NPs with $x_{\mathrm{Sm}}=0.02$.
\end{abstract}

\section{Introduction}

Nowadays, the development of new nanoscale materials has reached such complexity that engineered particles have the potential to be used for applications in various areas ranging from medicine to environment and electronics. The most studied engineered particles are the inorganic ones and mostly the ones that exhibit biological properties [1-3].

Hydroxyapatite, $\mathrm{Ca}_{10}\left(\mathrm{PO}_{4}\right)_{6}(\mathrm{OH})_{2}(\mathrm{HAp})$, is a calcium phosphate ceramic material and also the major inorganic component in bones and teeth of animals and humans [4]. Due to its excellent biocompatibility, bioactivity, and osteoconductivity, HAp is widely investigated and promoted in all biomaterial related research areas [5-8].

Apatites, especially HAp, have a strong affinity to ion substitution and a real potential for being used as structural matrices for materials design. Due to the tendency of substituting $\mathrm{Ca}^{2+}$ ions with other divalent elements, mostly metals such as $\mathrm{Ag}^{+}, \mathrm{Cu}^{2+}$, and $\mathrm{Zn}^{2+}$, hydroxyapatite is widely used to develop new compounds with exquisite properties. In the last years, the attention has been focused on the family of rare-earth elements as substituents of $\mathrm{Ca}^{2+}$ in the HAp structure [9-12]. Hydroxyapatite doped with rareearth ions is of interest in the area of biomaterials for bone related applications [13]. Lanthanides, also called rare-earth elements, are the family of elements between lanthanum and lutetium. These elements exhibit a pronounced biological activity, and they are able to replace $\mathrm{Ca}^{2+}$ ions in structured molecules [14-16]. One of the most important representative elements from the lanthanides family is samarium. $\mathrm{Sm}^{3+}$ ions are one of the most interesting ions to be analyzed due to their use in high-density optical storage, exquisite optical properties, and antibacterial properties [17, 18]. 
Recently [19], the primary tests concerning the adherence of Enterococcus faecalis ATCC 29212 (Gram-positive bacteria) to samarium doped hydroxyapatite showed high antibacterial activity against Enterococcus faecalis ATCC 29212. Here, we have synthesized the samarium doped hydroxyapatite bionanoparticles (Sm:HAp-NPs), with other concentrations of samarium $\left(x_{\mathrm{Sm}}=0, x_{\mathrm{Sm}}=0.02\right.$, and $\left.x_{\mathrm{Sm}}=0.05\right)$ by a quick and cheap method of synthesis. The present paper is mainly focused on the antibacterial activity of samarium doped hydroxyapatite bionanoparticles (Sm:HAp-NPs). The structural and morphological studies have confirmed the formation of Sm:HAp-NPs with the characteristics of pure apatite with good crystal structure. The particle sizes were measured by transmission electron microscopy (TEM) and using dynamic light scattering (DLS). The biocompatibility of the Sm:HAp-NPs was evaluated using in vitro assays, consisting in the quantification of hFOB 1.19 osteoblasts cells viability. The antibacterial activity of Sm:HAp-NPs with $x_{\mathrm{Sm}}$ $=0, x_{\mathrm{Sm}}=0.02$, and $x_{\mathrm{Sm}}=0.05$ was tested against Gramnegative bacteria (Pseudomonas aeruginosa and Escherichia coli) and Gram-positive bacteria (Enterococcus faecalis and Staphylococcus aureus).

\section{Materials and Methods}

2.1. Materials. All the reagents used for the synthesis, ammonium dihydrogen phosphate $\left[\left(\mathrm{NH}_{4}\right)_{2} \mathrm{HPO}_{4}\right]$, calcium nitrate tetrahydrate $\left[\mathrm{Ca}\left(\mathrm{NO}_{3}\right)_{2} \cdot 4 \mathrm{H}_{2} \mathrm{O}\right]$, Samarium(III) nitrate hexahydrate $\left[\mathrm{Sm}\left(\mathrm{NO}_{3}\right)_{3} \cdot 6 \mathrm{H}_{2} \mathrm{O}\right]$, and ammonia $\left(\mathrm{NH}_{3}\right)$, were purchased from Sigma-Aldrich and used without further purification.

2.2. Synthesis of Samarium Doped Hydroxyapatite. Nanocrystalline hydroxyapatite doped with $\mathrm{Sm}, \mathrm{Ca}_{10-x} \mathrm{Sm}_{x}$ $\left(\mathrm{PO}_{4}\right)_{6}(\mathrm{OH})_{2}$, with $x_{\mathrm{Sm}}=0, x_{\mathrm{Sm}}=0.02$, and $x_{\mathrm{Sm}}=0.05$, was obtained by setting the atomic ratio of $\mathrm{Sm} /[\mathrm{Sm}+\mathrm{Ca}]$ from $0 \%$ to $5 \%$ and $[\mathrm{Ca}+\mathrm{Sm}] / \mathrm{P}$ as 1.67 . The $\mathrm{Sm}\left(\mathrm{NO}_{3}\right)_{3} \cdot 6 \mathrm{H}_{2} \mathrm{O}$ and $\mathrm{Ca}\left(\mathrm{NO}_{3}\right)_{2} \cdot 4 \mathrm{H}_{2} \mathrm{O}$ were dissolved in $300 \mathrm{~mL}$ deionised water. On the other hand, the $\left(\mathrm{NH}_{4}\right)_{2} \mathrm{HPO}_{4}$ was dissolved in $300 \mathrm{~mL}$ deionised water. The $[\mathrm{Ca}+\mathrm{Sm}]$ solution was put into a Berzelius and stirred at $100^{\circ} \mathrm{C}$ for 30 minutes. The $\left(\mathrm{NH}_{4}\right)_{2} \mathrm{HPO}_{4}$ solution was added drop by drop into the [Ca $+\mathrm{Sm}$ ] solution and stirred for $2 \mathrm{~h}$. The $\mathrm{pH}$ was adjusted to 10 with $\mathrm{NH}_{3}$ and stirred continuously for 30 minutes. After the reaction, the deposited mixtures were washed several times with deionised water. The resulting material (Sm:HAp) was dried at $100^{\circ} \mathrm{C}$.

2.3. Characterisation. The X-ray diffraction measurements for Sm:HAp samples were recorded using a Bruker D8 Advance diffractometer, with nickel filtered $\mathrm{Cu} K \alpha(\lambda=$ $1.5418 \AA$ ) radiation, and a high efficiency one-dimensional detector (Lynx Eye type) operated in integration mode. The diffraction patterns were collected in the $2 \theta$ range between $15^{\circ}$ and $90^{\circ}$, with a step of $0.02^{\circ}$ and $34 \mathrm{~s}$ measuring time per step. The particle size was measured by the SZ-100 Nanoparticle Analyzer (Horiba) using dynamic light scattering (DLS). The signal obtained from the scattered light is fed into a multichannel correlator that generates a function used to determine the translational diffusion coefficient of the particles analyzed. The Stokes-Einstein equation is then used to calculate the particle size. The scanning electron microscopy (SEM) study was performed on a HITACHI S2600N-type microscope equipped with an energy dispersive X-ray attachment (EDAX/2001 device). Energy dispersive X-ray analysis, referred to as EDS or EDAX, was used to identify the elemental composition of materials. The functional groups present in samarium doped hydroxyapatite nanopowders were identified by Fourier transform infrared spectroscopy, FTIR, using a Spectrum BX spectrometer. The spectra were recorded on $10 \mathrm{~mm}$ diameter tablets containing $1 \% \mathrm{KBr}$ and 99\% samarium doped hydroxyapatite nanopowder in the range of 500 to $4000 \mathrm{~cm}^{-1}$ with a resolution of $4 \mathrm{~cm}^{-1}$.

2.4. Cell Cultures and Conditions. The hFOB 1.19 osteoblasts cells lines were purchased from American Type Culture Collection (ATCC CCL-12, Rockville, MD, USA). The cells were routinely maintained in Dulbecco's modified Eagle's medium (Sigma-Aldrich) supplemented with 10\% fetal bovine serum (Sigma-Aldrich) and $1 \%$ antibiotic antimycotic solution (including 10,000 units penicillin, $10 \mathrm{mg}$ streptomycin, and $25 \mu \mathrm{g}$ amphotericin B per $\mathrm{mL}$, Sigma-Aldrich) at $37^{\circ} \mathrm{C}$ in a humidified atmosphere of $5 \% \mathrm{CO}_{2}$. The cultured cells were loaded on samarium doped hydroxyapatite discs at a seeding density of $5 \times 10^{4}$ cells $/ \mathrm{cm}^{2}$ in 24 -well plates. Cells cultured in 24-well plates at the same seeding density were used as control.

2.5. In Vitro Cytotoxicity Assay. Biocompatibility test of the samarium doped hydroxyapatite $\left(x_{\mathrm{Sm}}=0, x_{\mathrm{Sm}}=0.02\right.$, and $\left.x_{\mathrm{Sm}}=0.05\right)$ discs has been made using primary osteoblast cell line. After osteoblast culture achievement, the cells were treated with trypsin $0.05 \%$ and spitted in 35/35 mm Petri dish. Cells were seeded at a density of 105 cells/mL in a Petri dish and incubated with samarium doped hydroxyapatite $\left(x_{\mathrm{Sm}}=\right.$ $0, x_{\mathrm{Sm}}=0.02$, and $\left.x_{\mathrm{Sm}}=0.05\right)$ for 4,12 , and 24 hours. The cell viability was determined by MTT (3-(4,5-dimethylthiazol2-yl)-2,5-diphenyltetrazolium bromide) reduction test. The cells were incubated $\left(5 \% \mathrm{CO}_{2}\right.$ atmosphere, $\left.T=37^{\circ} \mathrm{C}\right)$ for $4 \mathrm{~h}$ with MTT $(0.1 \mathrm{mg} / \mathrm{mL})$. The optical density at $595 \mathrm{~nm}$, for each well, was then determined using a Tecan multiplate reader (Tecan GENios, Grödic, Germany). The absorbance from the wells of cells cultured in the absence of ceramic discs was used as the $100 \%$ viability value.

2.6. Antimicrobial Studies. The antibacterial activity of Sm:HAp-NPs was assessed by the Kirby-Bauer disc diffusion technique against Gram-negative bacteria (Pseudomonas aeruginosa and Escherichia coli) and Gram-positive bacteria (Enterococcus faecalis and Staphylococcus aureus). The $5 \mathrm{mg}$ of the Sm:HAp-NPs $\left(x_{\mathrm{Sm}}=0, x_{\mathrm{Sm}}=0.02\right.$, and $\left.x_{\mathrm{Sm}}=0.05\right)$ was put in Sterile Whatman filter paper discs of $5 \mathrm{~mm}$ diameter. Finally, the sterile Whatman filter paper was placed on nutrient agar plates inoculated with bacterial cultures and incubated at $37^{\circ} \mathrm{C}$ for $24 \mathrm{~h}$. The zone of inhibition was measured by using antibiotic zone scale (Hi media) [20]. 
The effect of Sm:HAp-NPs on different phases of bacterial growth was evaluated by adding various concentration of Sm:HAp-NPs with $x_{\mathrm{Sm}}=0, x_{\mathrm{Sm}}=0.02$, and $x_{\mathrm{Sm}}=0.05$ $(40 \mathrm{mg} / \mathrm{mL})$ to overnight culture of Gram-negative bacteria (Pseudomonas aeruginosa and Escherichia coli) and Grampositive bacteria (Enterococcus faecalis and Staphylococcus aureus) in a $500 \mathrm{~mL}$ culture flask and kept in an incubator shaker at $27^{\circ} \mathrm{C}$ for $24 \mathrm{~h}$. The absorbance of the bacterial culture was measured at $620 \mathrm{~nm}$ at various concentrations (1, $0.5,0.25,0.125,0.62$, and $0.031 \mathrm{mg} / \mathrm{mL}$ ).

\section{Results and Discussion}

Hydroxyapatite doped with metal ions can play a key role in the development of modern chemotherapy on humans and animals. The hydroxyapatite doped with samarium ions with the molar compositions $\mathrm{Ca}_{10-x} \mathrm{Sm}\left(\mathrm{PO}_{4}\right)_{6}(\mathrm{OH})_{2}$, where $x_{\mathrm{Sm}}=$ $0, x_{\mathrm{Sm}}=0.02$, and $x_{\mathrm{Sm}}=0.05$, was synthesized by coprecipitation method. The structure, composition, and the qualitative analysis of chemical bonds of the samarium doped hydroxyapatite nanoparticles are discussed. Furthermore, the antimicrobial evaluation of Sm:HAp was performed, too.

The XRD patterns of Sm:HAp $\left(x_{\mathrm{Sm}}=0, x_{\mathrm{Sm}}=0.02\right.$, and $\left.x_{\mathrm{Sm}}=0.05\right)$ and the standard data for the hexagonal hydroxyapatite are shown in Figure 1. For all values of $x_{\mathrm{Sm}}$ the diffraction peaks can be well indexed to the hexagonal $\mathrm{Ca}_{10}\left(\mathrm{PO}_{4}\right)_{6}(\mathrm{OH})_{2}$ in $P 6_{3} m$ space group (ICDD-PDF number 9-432). In the XRD analysis of Sm:HAp, peaks for any new phase or impurity were not observed.

In good agreement with previous studies on $\mathrm{Sm}: \mathrm{HAp}$ [21$24]$, the XRD of Sm:HAp $\left(x_{\mathrm{Sm}}=0, x_{\mathrm{Sm}}=0.02\right.$, and $x_{\mathrm{Sm}}=$ 0.05 ) have also shown that samples with samarium doped hydroxyapatite exhibit the characteristics of pure apatite with good crystal structure.

The diffraction peak intensities of the Sm:HAp powders in the XRD spectra were reduced and the peak shapes were broadened when the Sm concentration increased. In good agreement with previous studies [25], the broadened peaks when Sm concentration increased in the Sm:HAp samples are attributed to the decrease of particle size.

In agreement with previous studies proposed by Ravindran et al. [24] and Shirkhanzadeh et al. [26], these results demonstrate that the $\mathrm{Sm}^{3+}$ ions have successfully substituted $\mathrm{Ca}^{2+}$ ions without affecting the crystal structure of the hydroxyapatite.

TEM images of Sm:HAp $\left(x_{\mathrm{Sm}}=0, x_{\mathrm{Sm}}=0.02\right.$, and $x_{\mathrm{Sm}}=$ $0.05)$ at low resolution are presented in Figure 2. The samples of samarium doped hydroxyapatite have a similar shape and maintain the morphology of pure HAp $\left(x_{\mathrm{Sm}}=0\right)$. We can see that the Sm:HAp nanoparticles were relatively uniform in shape for all the concentrations of samarium. The size of the $\mathrm{Sm}: H A p$ samples decreases when the samarium concentration increases. The synthesized Sm:HAp nanoparticles have ellipsoidal shape with regular surface and smoother edges.

The selected area electron diffraction (SAED) pattern recorded from an area containing a large number of nanoparticles is presented in Figure 2(d). The rings can be indexed as (002), (210), (211), (310), (222), (213), (004), and (304)

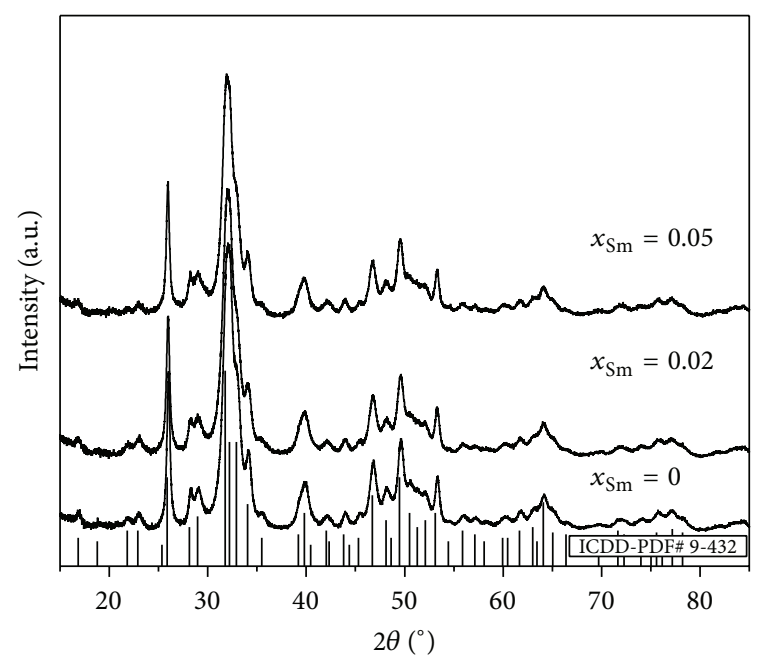

FIGURE 1: Comparative representation of the experimental XRD patterns of the Sm:HAp samples with $x_{\mathrm{Sm}}=0, x_{\mathrm{Sm}}=0.02$, and $x_{\mathrm{Sm}}=$ 0.05 and the characteristic lines of hydroxyapatite according to the ICDD-PDF number 9-432.

reflections of the hexagonal HAp. Because other reflections are not observed we can conclude that the results are in good agreement with the XRD results which indicated that the nanoparticles have a good crystal structure.

In Figure 3 the mean average size of samarium doped hydroxyapatite obtained by dynamic light scattering (DLS) measurements is presented. We can see that the diameter of the particles is similar to the TEM size. This result shows that the Sm:HAp nanoparticles in suspension are unagglomerated. On the other hand, the Sm:HAp nanoparticles are monodisperse in water.

The elemental composition of the Sm:HAp samples was highlighted by energy dispersive $\mathrm{X}$-ray (EDX) analysis (Figure 4). The EDX spectrum of $\mathrm{Ca}_{10-x} \mathrm{Sm}_{x}\left(\mathrm{PO}_{4}\right)_{6}(\mathrm{OH})_{2}$ confirmed the presence of calcium $(\mathrm{Ca})$, phosphorus $(\mathrm{P})$, oxygen $(\mathrm{O})$, and samarium $(\mathrm{Sm})$ in the samples with $x_{\mathrm{Sm}}$ $=0.02$ and $x_{\mathrm{Sm}}=0.05$. The EDX spectrum of Sm:HAp sample with $x_{\mathrm{Sm}}=0.02$ is shown in Figure 4. The EDX Mapping of Sm:HAp with $x_{\mathrm{Sm}}=0.02$ is also presented in Figure 4. EDX Mapping (element distribution images) provides in addition to the conventional SEM image a meaningful picture of the element distribution at the surface of $\mathrm{Ca}_{10-x} \mathrm{Sm}_{x}\left(\mathrm{PO}_{4}\right)_{6}(\mathrm{OH})_{2}$ samples. The uniform distributions of calcium $(\mathrm{Ca})$, phosphor $(\mathrm{P})$, oxygen $(\mathrm{O})$, and samarium $(\mathrm{Sm})$ in the samples have been confirmed.

The FTIR spectra of Sm:HAp (with $x_{\mathrm{Sm}}=0, x_{\mathrm{Sm}}=0.02$, and $\left.x_{\mathrm{Sm}}=0.05\right)$ samples synthesized by adapted coprecipitation method at $100^{\circ} \mathrm{C}$ are shown in Figure 5. The FTIR spectra of Sm:HAp samples for $x_{\mathrm{Sm}}=0, x_{\mathrm{Sm}}=0.02$, and $x_{\mathrm{Sm}}=$ 0.05 of samarium concentration are shown. The spectra of $\mathrm{Sm}:$ HAp samples with concentrations of samarium $x_{\mathrm{Sm}}=0$, $x_{\mathrm{Sm}}=0.02$, and $x_{\mathrm{Sm}}=0.05$ exhibited all vibrational modes corresponding to phosphate and hydroxyl groups present in HAp [27, 28]. The peak at $473 \mathrm{~cm}^{-1}$ is attributed to double degenerated bending mode of the $\mathrm{O}-\mathrm{P}-\mathrm{O}$ bond while 


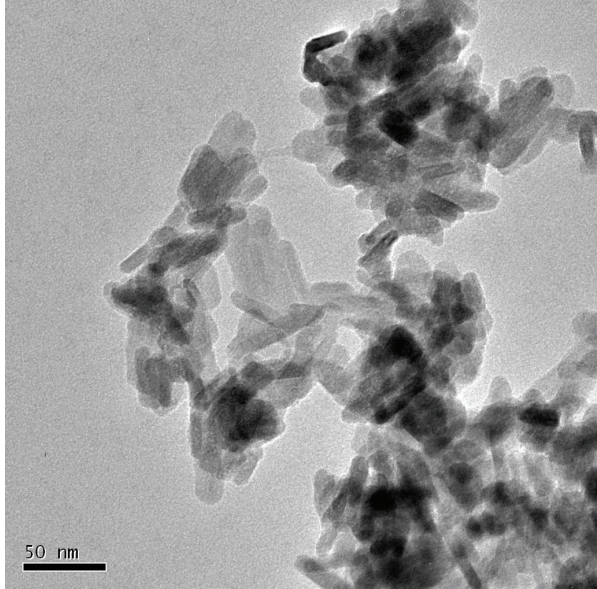

(a)

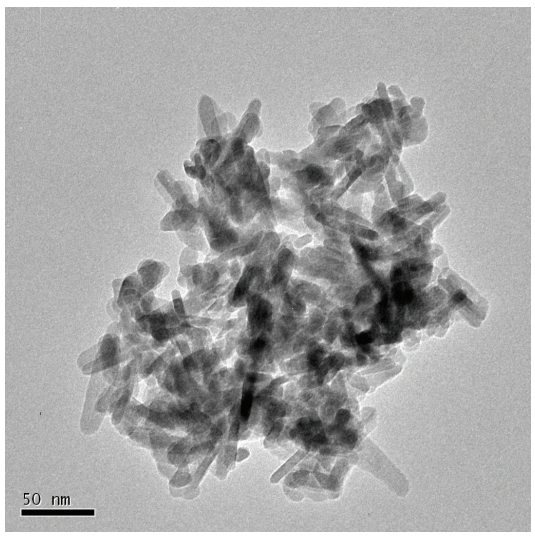

(c)

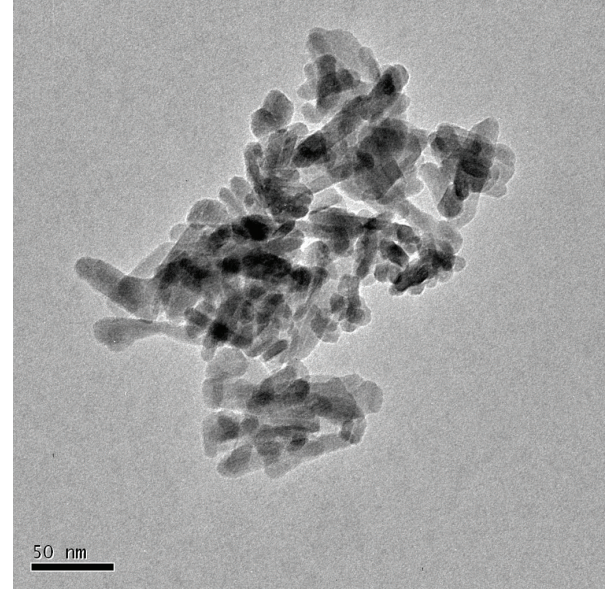

(b)

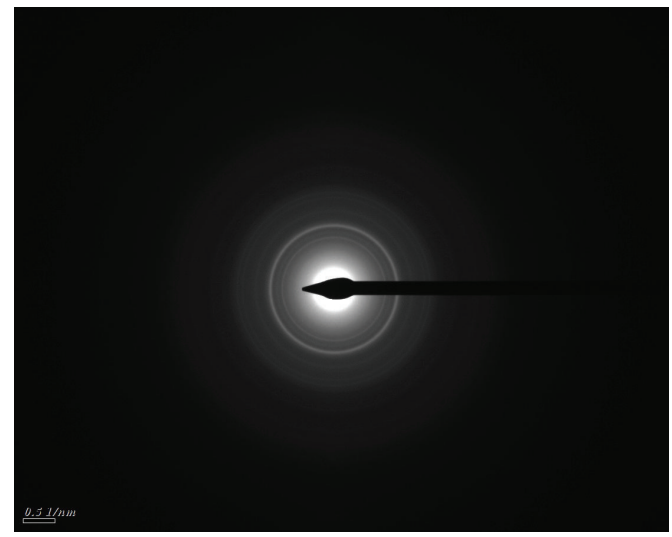

(d)

Figure 2: The TEM images at low resolution of Sm:HAp with $x_{\mathrm{Sm}}=0(\mathrm{a}), x_{\mathrm{Sm}}=0.02(\mathrm{~b})$, and $x_{\mathrm{Sm}}=0.05$ (c). The SAED analysis of Sm:HAp with $x_{\mathrm{Sm}}=0.02(\mathrm{~d})$.

the peaks at $1030-1100 \mathrm{~cm}^{-1}$ are attributed to triply degenerate asymmetric stretching mode of the $\mathrm{P}-\mathrm{O}$ bond. On the other hand, nondegenerated symmetric stretching mode of the $\mathrm{P}-\mathrm{O}$ bond is observed at $962 \mathrm{~cm}^{-1}$ [29]. The peaks at $563 \mathrm{~cm}^{-1}$ and $603 \mathrm{~cm}^{-1}$ are are characteristic to $\nu 4$ vibration of $\mathrm{PO}_{4}$. The bands at $872 \mathrm{~cm}^{-1}$ are attributed to $\mathrm{CO}_{3}{ }^{2-}$ ions and indicate B-type substitution, where $\mathrm{CO}_{3}{ }^{2-}$ substitutes the phosphate positions in the hydroxyapatite lattice [30, 31]. According to Nelson and Featherstone [32] and Barralet et al. [33] the B-type substitution is predominant in hydroxyapatite synthesized from precipitation reactions.

According to Predoi et al. $[5,34,35]$ the absorption peak in the region of $1600-1700 \mathrm{~cm}^{-1}$ is characteristic to $\mathrm{O}-\mathrm{H}$ bending mode and it is evidence of the presence of absorbed water in the synthesized samples. In recent studies on samarium doped hydroxyapatite nanoparticles (Sm:HApNPs), Han et al. [29] attributed the weak band in the region $3200-3600 \mathrm{~cm}^{-1}$ to the stretching vibration of structural OH bond. When the concentration of samarium increases in the samples, the hydroxyl vibration band in the region 3200$3600 \mathrm{~cm}^{-1}$ decreases in intensity. According to Barralet et al. [36] a decrease of the hydroxyl vibration peak intensity in the region $3200-3600 \mathrm{~cm}^{-1}$ and $\mathrm{PO}_{4}{ }^{3-}$ stretching mode at $960 \mathrm{~cm}^{-1}$ indicates an increase in the crystallinity of the particles. This decrease in crystallinity of the particles is consistent with the XRD results discussed before.

MTT assay is an assay which measures changes in colour for measuring cellular proliferation. It is used to determine cytotoxicity of potential medicinal agents and other toxic materials. The 3-(4,5-dimethylthiazol-2-yl)-2,5diphenyltetrazolium bromide is reduced to purple formazan in the mitochondria of living cells. To dissolve the insoluble purple formazan product into a coloured solution a solubilization solution is added. The hFOB 1.19 osteoblasts cells were permanently monitored to detect any possible influence due to samarium doped hydroxyapatite $\left(x_{\mathrm{Sm}}=0, x_{\mathrm{Sm}}=0.02\right.$, and $\left.x_{\mathrm{Sm}}=0.05\right)$ that might alter the cell growth, viability, and proliferation.

hFOB 1.19 osteoblast cells incubated with the samarium doped hydroxyapatite $\left(x_{\mathrm{Sm}}=0, x_{\mathrm{Sm}}=0.02\right.$, and $\left.x_{\mathrm{Sm}}=0.05\right)$ for 4,12 , and 24 hours presented a growth inhibition and the decrease of viability, relating to control (100\%). After 4 hours of exposure with Sm:HAp and diminish in proliferation of the osteoblast cells at $68.92 \%$ (Sm:HAp with $x_{\mathrm{Sm}}=0$ ), 

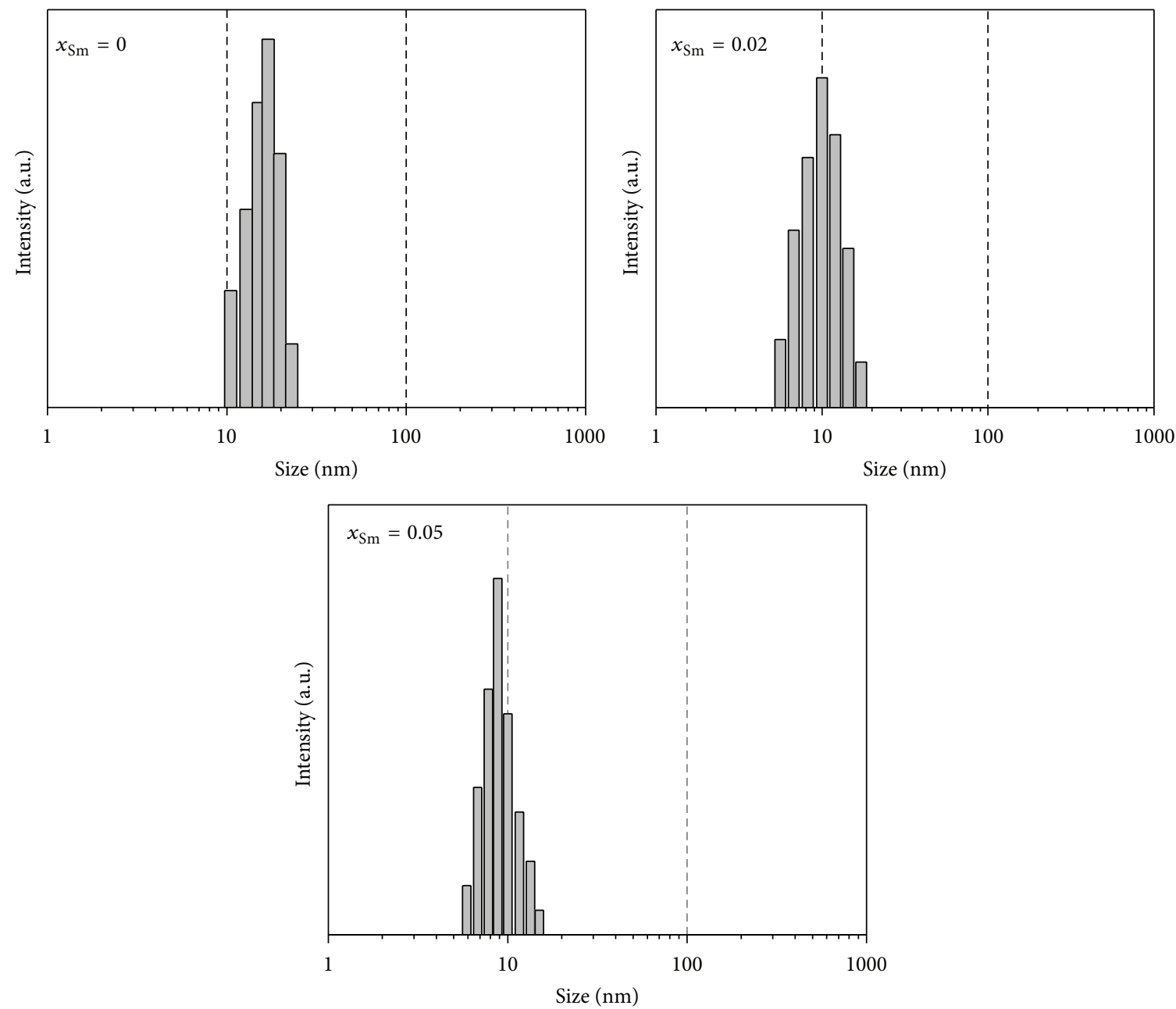

FIGURE 3: DLS showing mean average size of samarium doped hydroxyapatite.

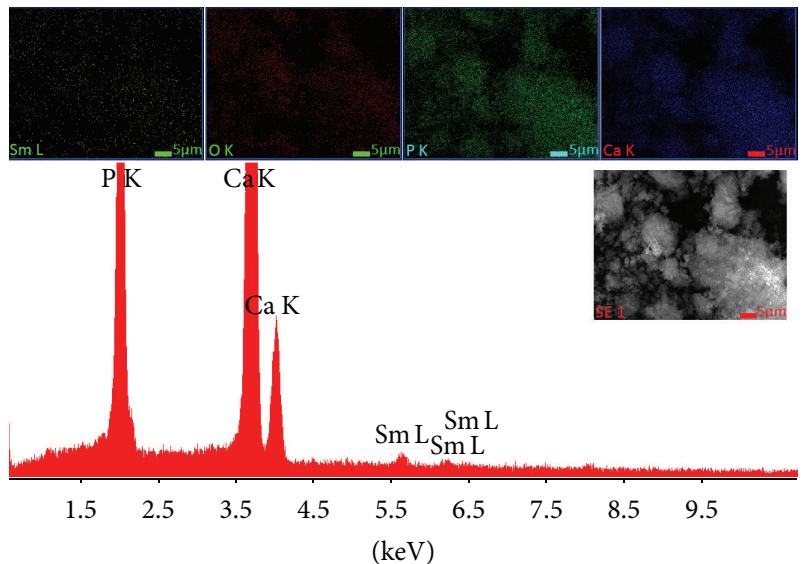

FIGURE 4: EDAX spectrum of the Sm:HAp $\left(x_{\mathrm{Sm}}=0.02\right)$ samples and simultaneous distributions of individual elements based on selected region of the sample.

68.56\% (Sm:HAp with $\left.x_{\mathrm{Sm}}=0.02\right)$, and 68.12\% (Sm:HAp with $\left.x_{\mathrm{Sm}}=0.05\right)$ a tendency of linear increase of viability and proliferation after 12 and 24 hours was observed. The increase of viability and proliferation of the osteoblast cells after 24 hours at around $100 \%$ relating to control was observed for all the samples (Figure 6).

Studies on the antimicrobial properties of these nanoparticles were also performed. The antimicrobial activity of Sm:HAp-NPs against Gram-negative (Pseudomonas aeruginosa and Escherichia coli) and Gram-positive (Enterococcus faecalis and Staphylococcus aureus) bacteria was evaluated.

Gram-negative bacteria can cause infections of surgical site or wound, bloodstream infections, pneumonia, and even meningitis. The Gram-negative bacteria have a unique structure of the outer membrane which gives them the ability to find new ways to be drug-resistant. The most common Gram-negative infections include those caused by Pseudomonas aeruginosa, Escherichia coli, Acinetobacter, and Klebsiella. According to Poole [37], one of the most worrisome characteristics of $P$. aeruginosa is its low antibiotic susceptibility. On the other hand, $P$. aeruginosa can easily develop resistance to antibiotics by mutation in chromosomally encoded genes. Escherichia coli is known for virulence in urinal tract infections and neonatal meningitis. It is known 

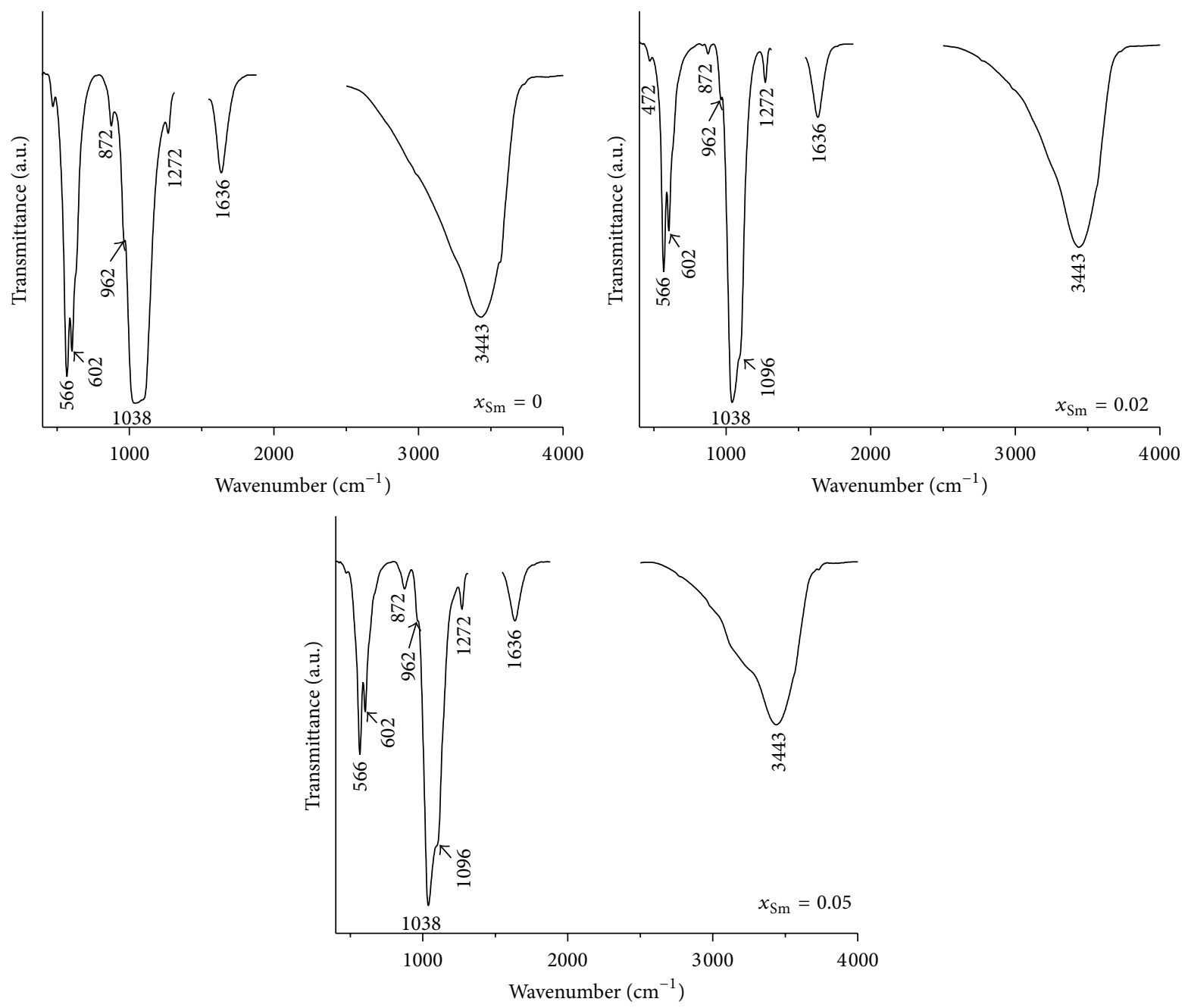

Figure 5: Infrared spectra in transmission mode of the Sm:HAp samples synthesized with $x_{\mathrm{Sm}}=0, x_{\mathrm{Sm}}=0.02$, and $x_{\mathrm{Sm}}=0.05$.

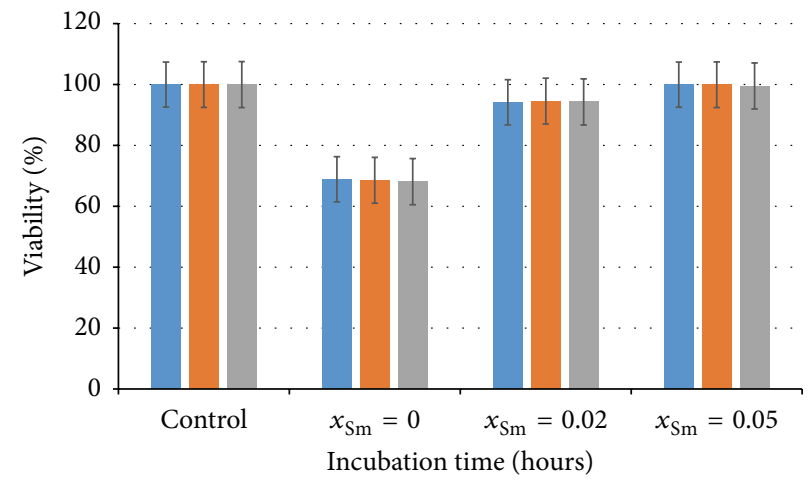

- 4
$-\quad 12$
$-\quad 24$

FIgURE 6: MTT assay in hFOB 1.19 osteoblast cells incubated on Sm:HAp $\left(x_{\mathrm{Sm}}=0, x_{\mathrm{Sm}}=0.02\right.$, and $\left.x_{\mathrm{Sm}}=0.05\right)$. 

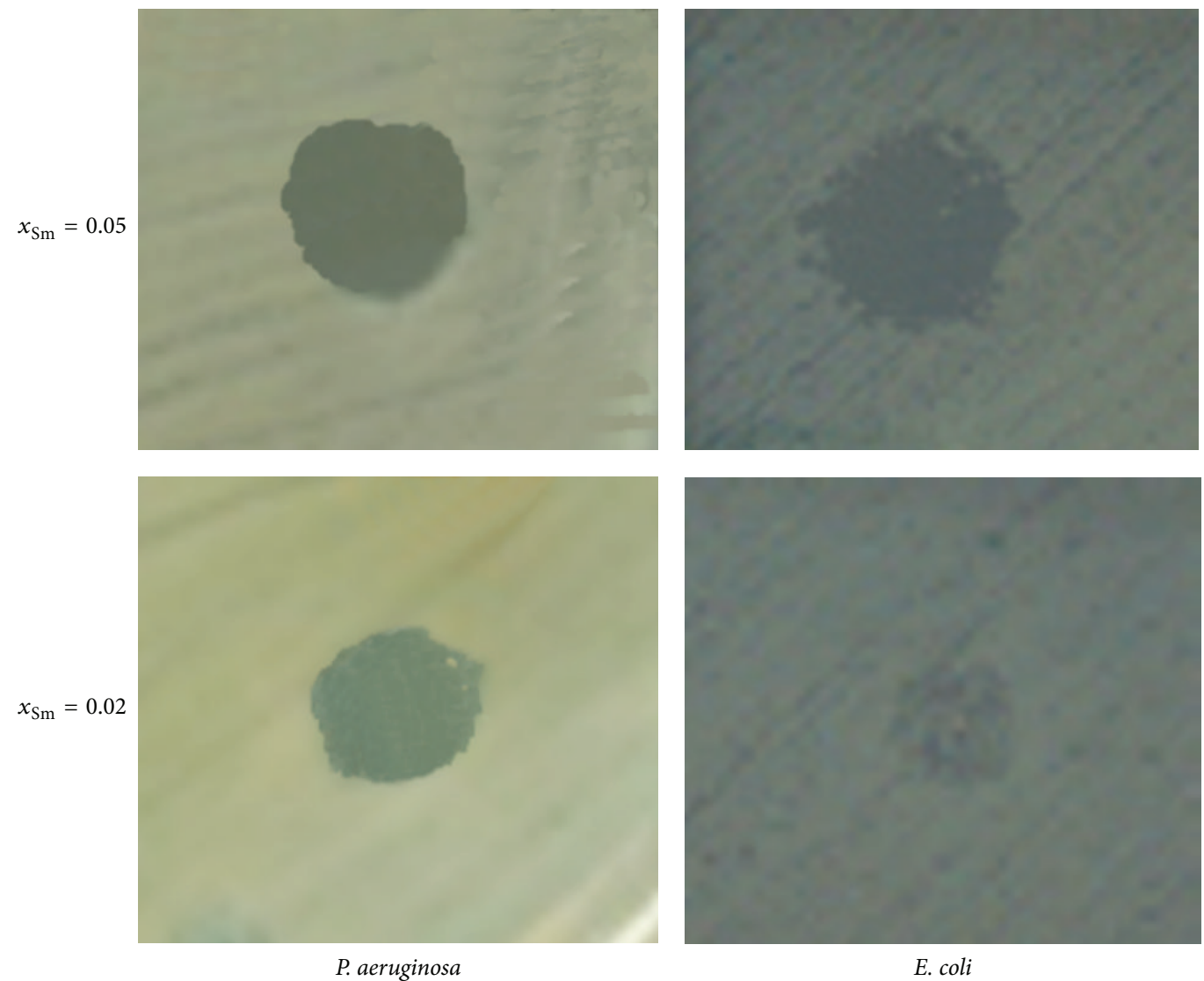

FiguRE 7: Qualitative antibacterial activity evaluation of Sm:HAp-NPs $\left(x_{\mathrm{Sm}}=0.02\right.$ and $\left.x_{\mathrm{Sm}}=0.05\right)$ on Pseudomonas aeruginosa and Escherichia coli Gram-negative bacteria.

that it is one of the main causes of urinary tract infections [38].

The results of qualitative antibacterial activity evaluation of Sm:HAp-NPs $\left(x_{\mathrm{Sm}}=0.02\right.$ and $\left.x_{\mathrm{Sm}}=0.05\right)$ on Gramnegative and Gram-positive bacteria are shown in Figures 7 and 8.

The antibacterial activity of Sm:HAp-NPs $\left(x_{\mathrm{Sm}}=0.02\right.$ and $\left.x_{\mathrm{Sm}}=0.05\right)$ was evaluated. For the Sm:HAp-NPs with $x_{\mathrm{Sm}}=0$ no activity against the Pseudomonas aeruginosa, Escherichia coli, Enterococcus faecalis, and Staphylococcus aureus was observed. On the other hand, the interactions of Sm:HApNPs $\left(x_{\mathrm{Sm}}=0.02\right.$ and $\left.x_{\mathrm{Sm}}=0.05\right)$ with Gram-negative and Gram-positive tested bacteria were different. The different interaction between our compounds and microbial strains tested could be due to differences occurring in the microbial wall structures. The qualitative antibacterial activity evaluation on Sm:HAp-NPs was revealed by a clear zone of inhibition when the concentrations were $x_{\mathrm{Sm}}=0.02$ and $x_{\mathrm{Sm}}$ $=0.05$. A significant antibacterial activity was observed on Sm:HAp-NPs with $x_{\text {Sm }}=0.02$ for all of the bacteria used.

In Figure 9 the antibacterial activity of Sm:HAp-NPs $\left(x_{\mathrm{Sm}}=0, x_{\mathrm{Sm}}=0.02\right.$, and $\left.x_{\mathrm{Sm}}=0.05\right)$ on Gram-negative bacteria (Pseudomonas aeruginosa and Escherichia coli) is shown. We can see that the $P$. aeruginosa was inhibited when concentrations of Sm:HAp-NPs in the samples with $x_{\mathrm{Sm}}=0.02$ and $x_{\mathrm{Sm}}=0.05$ were higher than $0.125 \mathrm{mg} / \mathrm{mL}$.
When concentrations of Sm:HAp-NPs in the samples with $x_{\mathrm{Sm}}=0.02$ and $x_{\mathrm{Sm}}=0.05$ were lower than $0.125 \mathrm{mg} / \mathrm{mL}$, an increase in microbial activity for the sample with $x_{\mathrm{Sm}}=$ 0.02 was observed, while for the samples with $x_{\mathrm{Sm}}=0.05$ the values obtained are comparable to the control sample $\left(\mathrm{M}^{+}\right)$. A linear increase of antimicrobial activity of $P$. aeruginosa has been observed when concentrations of Sm:HAp-NPs in the samples with $x_{\mathrm{Sm}}=0.02$ were higher than $0.125 \mathrm{mg} / \mathrm{mL}$. A linear increase in the antimicrobial activity is also observed for concentrations of Sm:HAp-NPs with $x_{\text {Sm }}=0.05$ in the range $0.25-0.5 \mathrm{mg} / \mathrm{mL}$. When the concentration of Sm:HApNPs in the samples with $x_{\mathrm{Sm}}=0.05$ is equal to 1 , the antibacterial effect is maximum, and we can say that the $P$. aeruginosa was completely killed. For all the concentrations of Sm:HAp-NPs in the samples with $x_{\mathrm{Sm}}=0$ an increase in microbial activity was observed compared with that of the control $\left(\mathrm{M}^{+}\right)$. The antibacterial activity of Sm:HAp-NPs $\left(x_{\mathrm{Sm}}\right.$ $=0, x_{\mathrm{Sm}}=0.02$, and $\left.x_{\mathrm{Sm}}=0.05\right)$ on $E$. coli can be seen in Figure 9(b). The antibacterial activity of Sm:HAp-NPs on E. coli is observed for concentrations of Sm:HAp-NPs with $x_{\mathrm{Sm}}=0.05$ in the range $0.031-1.0 \mathrm{mg} / \mathrm{mL}$. For this sample (Sm:HAp-NPs with $\left.x_{\mathrm{Sm}}=0.05\right)$ a significant increase of antibacterial activity of $E$. coli was observed in the range $0.5-$ $1 \mathrm{mg} / \mathrm{mL}$. An increase in microbial activity compared with that of the control $\left(\mathrm{M}^{+}\right)$was observed in the region of $0.031-$ $0.5 \mathrm{mg} / \mathrm{mL}$ for concentration of Sm:HAp-NPs with $x_{\mathrm{Sm}}=0.02$ 

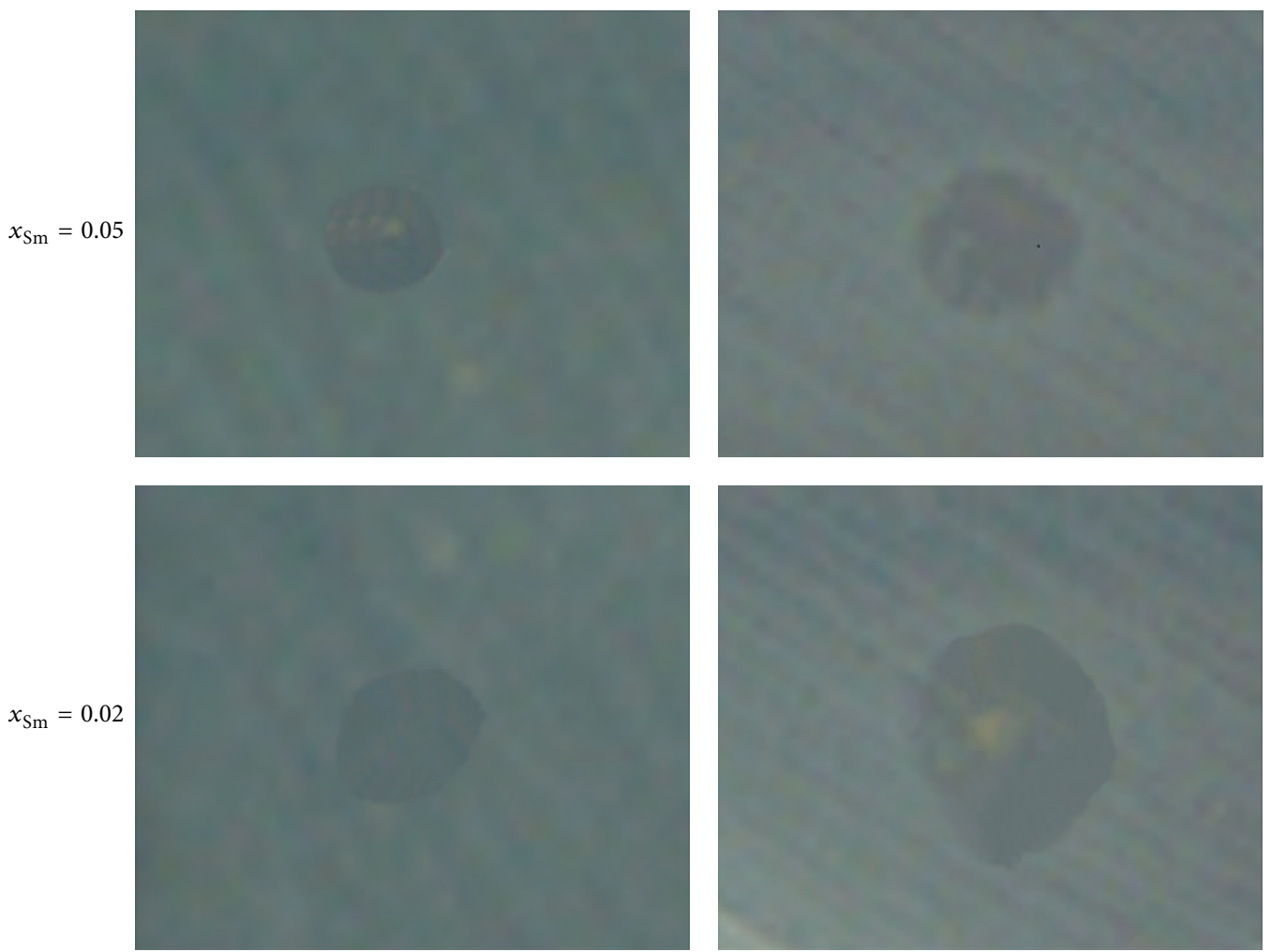

E. faecalis

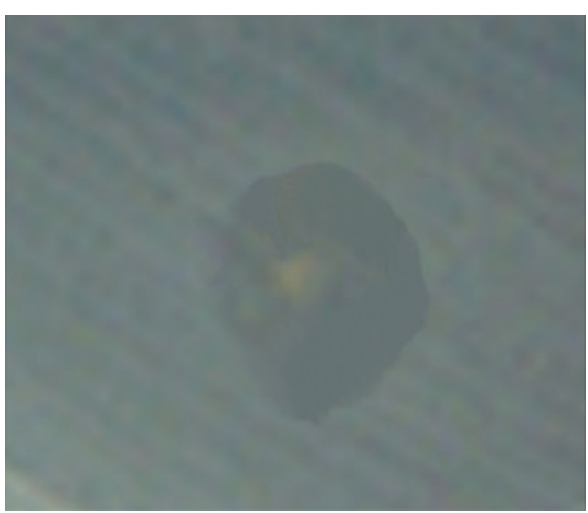

S. aureus

FIGURE 8: Qualitative antibacterial activity evaluation of Sm:HAp-NPs $\left(x_{\mathrm{Sm}}=0.02\right.$ and $\left.x_{\mathrm{Sm}}=0.05\right)$ against Enterococcus faecalis and Staphylococcus aureus Gram-positive bacteria.

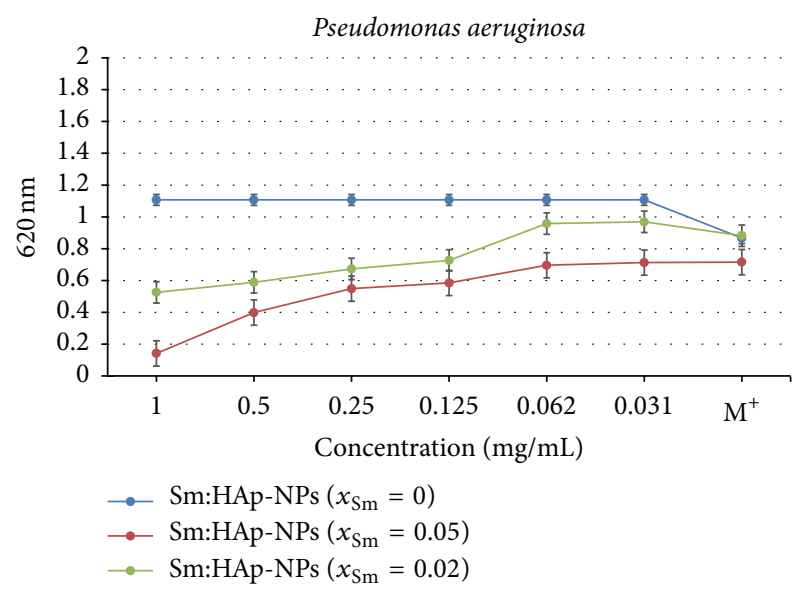

(a)

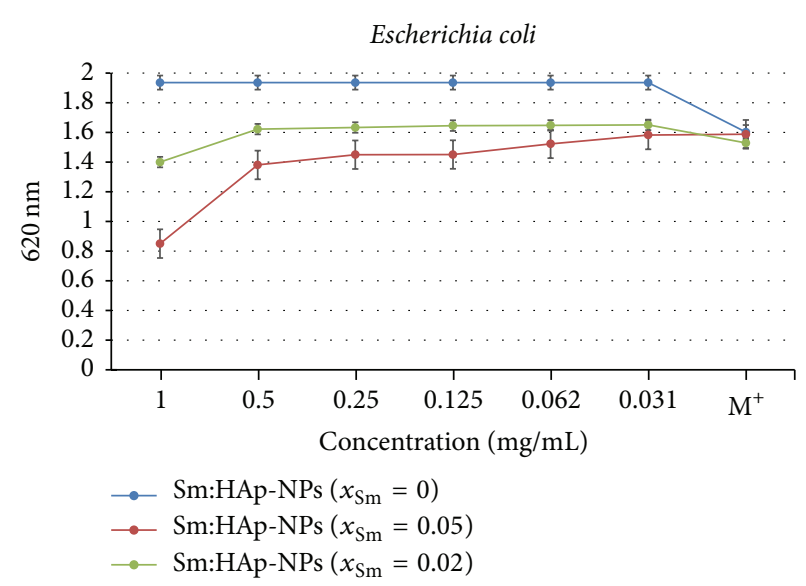

(b)

Figure 9: The antibacterial activity of Sm:HAp-NPs $\left(x_{\mathrm{Sm}}=0, x_{\mathrm{Sm}}=0.02\right.$, and $\left.x_{\mathrm{Sm}}=0.05\right)$ on Pseudomonas aeruginosa (a) and Escherichia coli (b) after $24 \mathrm{~h}$.

and $x_{\mathrm{Sm}}=0$. In the region $0.5-1 \mathrm{mg} / \mathrm{mL}$, the microbial activity remains constant compared with the microbial activity in the region $0.031-0.5 \mathrm{mg} / \mathrm{mL}$ for the concentration of Sm:HApNPs with $x_{\mathrm{Sm}}=0$, while, for concentration of Sm:HAp-NPs with $x_{\mathrm{Sm}}=0.02$, a significant decrease is observed.

The antibacterial activity of Sm:HAp-NPs $\left(x_{\mathrm{Sm}}=0\right.$, $x_{\mathrm{Sm}}=0.02$, and $\left.x_{\mathrm{Sm}}=0.05\right)$ on Gram-positive bacteria
(Enterococcus faecalis and Staphylococcus aureus) is shown in Figure 10. Gram-positive and Gram-negative bacteria have similar internal structures while the external structure is very different. The most common Gram-positive bacteria such as Enterococcus, Staphylococcus, and Streptococcus are responsible for a large number of serious infections worldwide. Based on the recent update from the National Healthcare Safety 


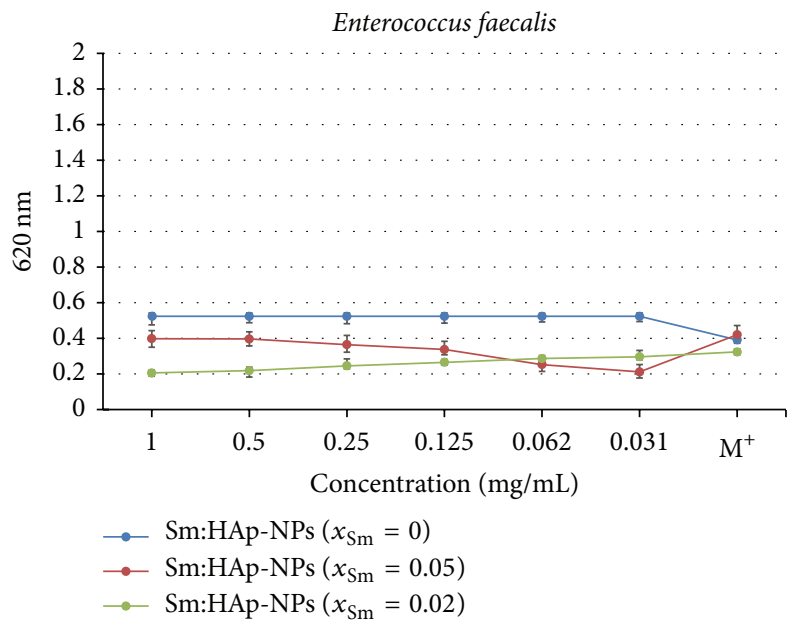

(a)

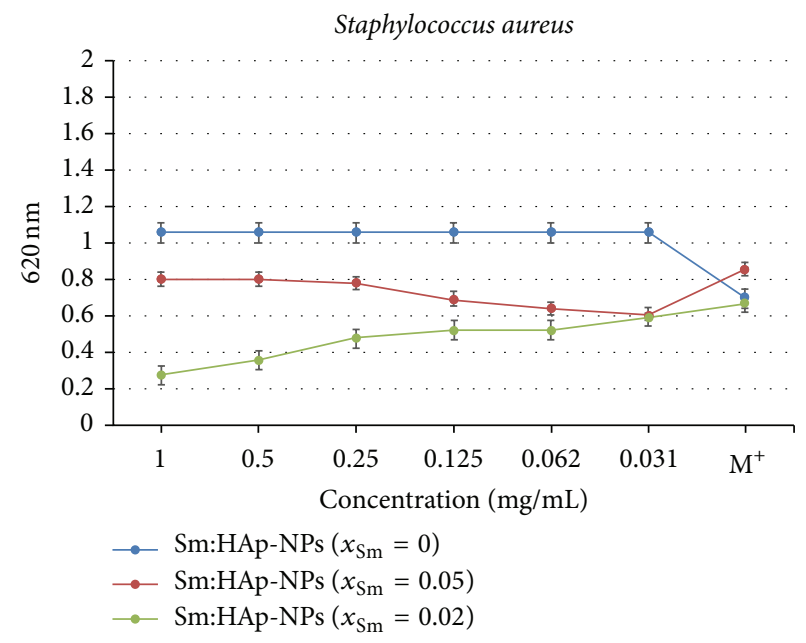

(b)

Figure 10: The antibacterial activity of Sm:HAp-NPs $\left(x_{\mathrm{Sm}}=0, x_{\mathrm{Sm}}=0.02\right.$, and $\left.x_{\mathrm{Sm}}=0.05\right)$ on Enterococcus faecalis (a) and Staphylococcus aureus (b) after $24 \mathrm{~h}$.

Network (NHSN) for surveillance of antimicrobial-resistant pathogens [39], S. aureus and Enterococcus faecalis are the most frequently isolated organisms. On the other hand, $S$. aureus and Enterococcus faecalis are the most commonly present organisms in hospitals in Europe [40].

Figure 10(a) displays the antibacterial performance against Gram-positive, Enterococcus faecalis, bacteria obtained for the Sm:HAp-NPs $\left(x_{\mathrm{Sm}}=0, x_{\mathrm{Sm}}=0.02\right.$, and $x_{\mathrm{Sm}}$ $=0.05)$. The antimicrobial test showed that Sm:HAp-NPs with $x_{\mathrm{Sm}}=0$ caused an increase in the microbial activity of Enterococcus faecalis compared to that of the control $\left(\mathrm{M}^{+}\right)$. Antibacterial activity of Sm:HAp-NPs samples with $x_{\mathrm{Sm}}=0.02$ increased with an increase of the Sm:HAp-NPs concentration from 0.031 to $1 \mathrm{mg} / \mathrm{mL}$. The Sm:HAp-NPs samples with $x_{\mathrm{Sm}}=0.05$ showed a weak antibacterial activity for high concentrations of Sm:HAp-NPs from 0.125 to $1 \mathrm{mg} / \mathrm{mL}$. For low concentrations of Sm:HAp-NPs $\left(x_{\mathrm{Sm}}=\right.$ 0.05 ) from 0.031 to $0.125 \mathrm{mg} / \mathrm{mL}$ a high antibacterial activity of Enterococcus faecalis has been noticed. In Figure 10(b) the antibacterial activity of Sm:HAp-NPs at various concentrations from 0.031 to $1 \mathrm{mg} / \mathrm{mL}$ on Staphylococcus aureus is shown when $x_{\mathrm{Sm}}=0,0.02$, and 0.05 . When $x_{\mathrm{Sm}}=0$ the microbial activity is higher compared to that of the control $\left(\mathrm{M}^{+}\right)$for all tested concentrations. At low concentrations from 0.031 to $0.125 \mathrm{mg} / \mathrm{mL}$, the antibacterial activity of Sm:HAp-NPs $\left(x_{\mathrm{Sm}}=0.05\right)$ is high, while, for higher concentrations of $0.25 \mathrm{mg} / \mathrm{mL}$, the antibacterial activity decreases reaching values close to that of the control $\left(\mathrm{M}^{+}\right)$. A growth of the inhibitory effect on $S$. aureus was observed for all concentrations of Sm:HAp-NPs with $x_{\mathrm{Sm}}$ $=0.02$. For the concentrations from 0.5 to $1 \mathrm{mg} / \mathrm{mL}$ of $\mathrm{Sm}: \mathrm{HAp}-\mathrm{NPs}\left(x_{\mathrm{Sm}}=0.02\right)$ a very good antibacterial activity was noticed.

A growing proportion of Gram-negative and Grampositive organisms display reduced susceptibility to antibiotics in communities and hospitals [41, 42]. According to
Woodford and Livermore [43] the resistant bacteria have a significant impact on overall healthcare utilization and costs. As a result of the increased antibiotic resistance of the various microorganisms like bacteria, molds, viruses, and so forth, new antimicrobial agents that could be used to prevent infections are made. For the first time, this study has examined the synthesis of samarium doped hydroxyapatite at low temperature by coprecipitation method and its antibacterial activity. It could be concluded that the Sm:HAp-NPs have the antibacterial potential for treating wounds or even for covering medical instruments.

\section{Conclusions}

Samarium doped hydroxyapatite nanoparticles were successfully synthesized by coprecipitation method. hFOB 1.19 osteoblast cells incubated with the samarium doped hydroxyapatite $\left(x_{\mathrm{Sm}}=0, x_{\mathrm{Sm}}=0.02\right.$, and $\left.x_{\mathrm{Sm}}=0.05\right)$ exhibit an increase of viability and proliferation after 24 hours at around $100 \%$ relating to control for all the samples.

The Sm:HAp-NPs were tested for their antibacterial activity. The Sm:HAp-NPs with $x_{\mathrm{Sm}}=0,0.02$, and 0.05 have antimicrobial property against the Gram-negative and Grampositive bacteria depending on the concentration of samarium. The bioproperties of Sm:HAp-NPs can be controlled by varying the samarium in hydroxyapatite. The antibacterial properties of Sm:HAp-NPs can lead to increasing their applicability in medical or environmental area.

\section{Conflict of Interests}

The authors declare that there is no conflict of interests regarding the publication of this paper. 


\section{Acknowledgments}

The work has been funded by the Sectoral Operational Programme Human Resources Development 2007-2013 of the Ministry of European Funds through the Financial Agreement POSDRU/159/1.5/S/134398. The authors are grateful to Professor M. C. Chifiriuc (University of Bucharest, Faculty of Biology), for performing antimicrobial studies and their helpful discussions.

\section{References}

[1] M. G. Albu, D. M. Suflet, G. C. Chitanu, P. Budrugeac, I. Titorencu, and V. Trandafir, "Biocomposites based on collagen and phosphorylated dextran for bone regeneration," Journal of Materials Research, vol. 27, no. 7, pp. 1086-1096, 2012.

[2] A. Ficai, E. Andronescu, D. Ficai, M. Sonmez, M. G. Albu, and G. Voicu, "Mimicking the morphology of long bone," Central European Journal of Chemistry, vol. 10, no. 6, pp. 1949-1953, 2012.

[3] A. Groza, A. Surmeian, C. Diplasu, M. Ganciu, P. Chapon, and I. I. Popescu, "Spectral investigations of the processes observed at polydimetylsiloxane polymer-substrate interface during its polymerization process in negative and positive corona discharges," Journal of Optoelectronics and Advanced Materials, vol. 12, no. 11, pp. 2311-2314, 2010.

[4] S. R. Ramanan and R. Venkatesh, "A study of hydroxyapatite fibers prepared via sol-gel route," Materials Letters, vol. 58, no. 26, pp. 3320-3323, 2004.

[5] A. Costescu, C. S. Ciobanu, S. L. Iconaru et al., "Fabrication, characterization, and antimicrobial activity, evaluation of low silver concentrations in silver-doped hydroxyapatite nanoparticles," Journal of Nanomaterials, vol. 2013, Article ID 194854, 9 pages, 2013.

[6] C. S. Ciobanu, F. Massuyeau, L. V. Constantin, and D. Predoi, "Structural and physical properties of antibacterial Ag-doped nano-hydroxyapatite synthesized at $100^{\circ} \mathrm{C}$," Nanoscale Research Letters, vol. 6, article 613, 2011.

[7] A. Ficai, M. G. Albu, M. Birsan et al., "Collagen hydrolysate based collagen/hydroxyapatite composite materials," Journal of Molecular Structure, vol. 1037, pp. 154-159, 2013.

[8] A. Groza, "Review of the processes identified during the polymerization of organic and organosilicon liquid films in atmospheric pressure air corona discharges," Romanian Reports in Physics, vol. 64, no. 4, pp. 1227-1242, 2012.

[9] G. Blasse, "Influence of local charge compensation on site occupation and luminescence of apatites," Journal of Solid State Chemistry, vol. 14, no. 2, pp. 181-184, 1975.

[10] S. A. Payne, L. D. DeLoach, L. K. Smith et al., "Ytterbium-doped apatite-structure crystals: a new class of laser materials," Journal of Applied Physics, vol. 76, no. 1, pp. 497-503, 1994.

[11] W. Suchanek and M. Yoshimura, "Processing and properties of hydroxyapatite-based biomaterials for use as hard tissue replacement implants," Journal of Materials Research, vol. 13, no. 1, pp. 94-117, 1998.

[12] J. Rakovan, R. J. Reeder, E. J. Elzinga, D. J. Cherniak, C. D. Tait, and D. E. Morris, "Structural characterization of U(VI) in apatite by X-ray absorption spectroscopy," Environmental Science \& Technology, vol. 36, no. 14, pp. 3114-3117, 2002.
[13] A. Aissa, M. Debbabi, M. Gruselle et al., "Sorption of tartrate ions to lanthanum (III)-modified calcium fluor- and hydroxyapatite," Journal of Colloid and Interface Science, vol. 330, no. 1, pp. 20-28, 2009.

[14] S. P. Fricker, "The therapeutic application of lanthanides", Chemical Society Reviews, vol. 35, no. 6, pp. 524-533, 2006.

[15] T. Matsuda, C. Yamanaka, and M. Ikeya, "ESR study of $\mathrm{Gd}^{3+}$ and $\mathrm{Mn}^{2+}$ ions sorbed on hydroxyapatite," Applied Radiation and Isotopes, vol. 62, no. 2, pp. 353-357, 2005.

[16] J. Coelho, N. S. Hussain, P. S. Gomes et al., "Development and characterization of lanthanides doped hydroxyapatite composites for bone tissue application," in Current Trends on Glass and Ceramic Materials, pp. 87-115, 2012.

[17] V. Venkatramu, P. Babu, C. K. Jayasankar, T. Tröster, W. Sievers, and G. Wortmann, "Optical spectroscopy of $\mathrm{Sm}^{3+}$ ions in phosphate and fluorophosphate glasses," Optical Materials, vol. 29, no. 11, pp. 1429-1439, 2007.

[18] M. S. Refat, F. M. Al-Azab, H. M. A. Al-Maydama, R. R. Amin, and Y. M. S. Jamil, "Synthesis and in vitro microbial evaluation of $\mathrm{La}(\mathrm{III}), \mathrm{Ce}(\mathrm{III}), \mathrm{Sm}(\mathrm{III})$ and $\mathrm{Y}(\mathrm{III})$ metal complexes of vitamin B6 drug," Spectrochimica Acta Part A: Molecular and Biomolecular Spectroscopy, vol. 127, pp. 196-215, 2014.

[19] C. S. Ciobanu, C. L. Popa, and D. Predoi, "Sm:HAp nanopowders present antibacterial activity against Enterococcus faecalis," Journal of Nanomaterials, vol. 2014, Article ID 780686, 9 pages, 2014.

[20] M. G. Cormican, W. W. Wilke, M. S. Barrett, M. A. Pfaller, and R. N. Jones, "Phenotypic detection of mec A-positive staphylococcal blood stream isolates: high accuracy of simple disk diffusion tests," Diagnostic Microbiology and Infectious Disease, vol. 25, no. 3, pp. 107-112, 1996.

[21] C. L. Popa, C. S. Ciobanu, S. L. Iconaru et al., "Systematic investigation and in vitro biocompatibility studies on mesoporous europium doped hydroxyapatite," Central European Journal of Chemistry, vol. 12, no. 10, pp. 1032-1046, 2014.

[22] C. S. Ciobanu, S. L. Iconaru, P. Le Coustumer, L. V. Constantin, and D. Predoi, "Antibacterial activity of silver-doped hydroxyapatite nanoparticles against gram-positive and gram-negative bacteria," Nanoscale Research Letters, vol. 7, article 324, 2012.

[23] C. S. Ciobanu, S. L. Iconaru, M. C. Chifiriuc, A. Costescu, P. Le Coustumer, and D. Predoi, "Synthesis and antimicrobial activity of silver-doped hydroxyapatite nanoparticles," BioMed Research International, vol. 2013, Article ID 916218, 10 pages, 2013.

[24] A. Ravindran, A. Singh, A. M. Raichur, N. Chandrasekaran, and A. Mukherjee, "Studies on interaction of colloidal Ag nanoparticles with Bovine Serum Albumin (BSA)," Colloids and Surfaces B: Biointerfaces, vol. 76, no. 1, pp. 32-37, 2010.

[25] S.-L. Iconaru, M. Motelica-Heino, and D. Predoi, "Study on europium-doped hydroxyapatite nanoparticles by fourier transform infrared spectroscopy and their antimicrobial properties," Journal of Spectroscopy, vol. 2013, Article ID 284285, 10 pages, 2013.

[26] M. Shirkhanzadeh, M. Azadegan, and G. Q. Liu, "Bioactive delivery systems for the slow release of antibiotics: incorporation of $\mathrm{Ag}^{+}$ions into micro-porous hydroxyapatite coatings," Materials Letters, vol. 24, no. 1-3, pp. 7-12, 1995.

[27] C. S. Ciobanu, S. L. Iconaru, F. Massuyeau, L. V. Constantin, A. Costescu, and D. Predoi, "Synthesis, structure, and luminescent properties of europium-doped hydroxyapatite nanocrystalline powders," Journal of Nanomaterials, vol. 2012, Article ID 942801, 9 pages, 2012. 
[28] C. S. Ciobanu, S. L. Iconaru, P. Le Coustumer, and D. Predoi, "Vibrational investigations of silver-doped hydroxyapatite with antibacterial properties," Journal of Spectroscopy, vol. 2013, Article ID 471061, 5 pages, 2013.

[29] Y. J. Han, S. C. J. Loo, N. T. Phung, F. Boey, and J. Ma, "Controlled size and morphology of EDTMP-doped hydroxyapatite nanoparticles as model for 153Samarium-EDTMP doping," Journal of Materials Science: Materials in Medicine, vol. 19, no. 9, pp. 2993-3003, 2008.

[30] W. H. Emerson and E. E. Fischer, "The infrared absorption spectra of carbonate in calcified tissues," Archives of Oral Biology, vol. 7, no. 6, pp. 671-683, 1962.

[31] V. Jokanović, D. Izvonar, M. D. Dramićanin et al., "Hydrothermal synthesis and nanostructure of carbonated calcium hydroxyapatite," Journal of Materials Science: Materials in Medicine, vol. 17, no. 6, pp. 539-546, 2006.

[32] D. G. A. Nelson and J. D. B. Featherstone, "Preparation, analysis, and characterization of carbonated apatites," Calcified Tissue International, vol. 34, supplement 2, pp. S69-S81, 1982.

[33] J. Barralet, S. Best, and W. Bonfield, "Carbonate substitution in precipitated hydroxyapatite: an investigation into the effects of reaction temperature and bicarbonate ion concentration," Journal of Biomedical Materials Research, vol. 41, no. 1, pp. 7986, 1998.

[34] D. Predoi, R. V. Ghita, F. Ungureanu, C. C. Negrila, R. A. Vatasescu-Balcan, and M. Costache, "Characteristics of hydroxyapatite thin films," Journal of Optoelectronics and Advanced Materials, vol. 9, no. 12, pp. 3827-3831, 2007.

[35] A. Groza, A. Surmeian, M. Ganciu, and I. I. Popescu, "Infrared spectral investigation of the linseed oil polymerization in a corona discharge in air at atmospheric pressure," Europhysics Letters, vol. 68, no. 5, pp. 652-657, 2004.

[36] J. Barralet, J. C. Knowles, S. Best, and W. Bonfield, “Thermal decomposition of synthesised carbonate hydroxyapatite," Journal of Materials Science: Materials in Medicine, vol. 13, no. 6, pp. 529-533, 2002.

[37] K. Poole, "Efflux-mediated multiresistance in gram-negative bacteria," Clinical Microbiology and Infection, vol. 10, no. 1, pp. 12-26, 2004.

[38] D. W. Hilbert, Uropathogenic Escherichia coli: The Pre-Eminent Urinary Tract Infection Pathogen, Nova Publishers, 2013.

[39] D. M. Sievert, P. Ricks, J. R. Edwards et al., "Antimicrobialresistant pathogens associated with healthcare- associated infections: Summary of data reported to the national healthcare safety network at the centers for disease control and prevention, 2009-2010," Infection Control and Hospital Epidemiology, vol. 34, no. 1, pp. 1-14, 2013.

[40] J.-L. Vincent, J. Rello, J. Marshall et al., "International study of the prevalence and outcomes of infection in intensive care units," The Journal of the American Medical Association, vol. 302, no. 21, pp. 2323-2329, 2009.

[41] S. E. Cosgrove, Y. Qi, K. S. Kaye, S. Harbarth, A. W. Karchmer, and Y. Carmeli, "The impact of methicillin resistance in Staphylococcus aureus bacteremia on patient outcomes: mortality, length of stay, and hospital charges," Infection Control and Hospital Epidemiology, vol. 26, no. 2, pp. 166-174, 2005.

[42] J. M. Rybak, K. E. Barber, and M. J. Rybak, "Current and prospective treatments for multidrug-resistant gram-positive infections," Expert Opinion on Pharmacotherapy, vol. 14, no. 14, pp. 1919-1932, 2013.
[43] N. Woodford and D. M. Livermore, "Infections caused by Gram-positive bacteria: a review of the global challenge," Journal of Infection, vol. 59, supplement 1, pp. S4-S16, 2009. 

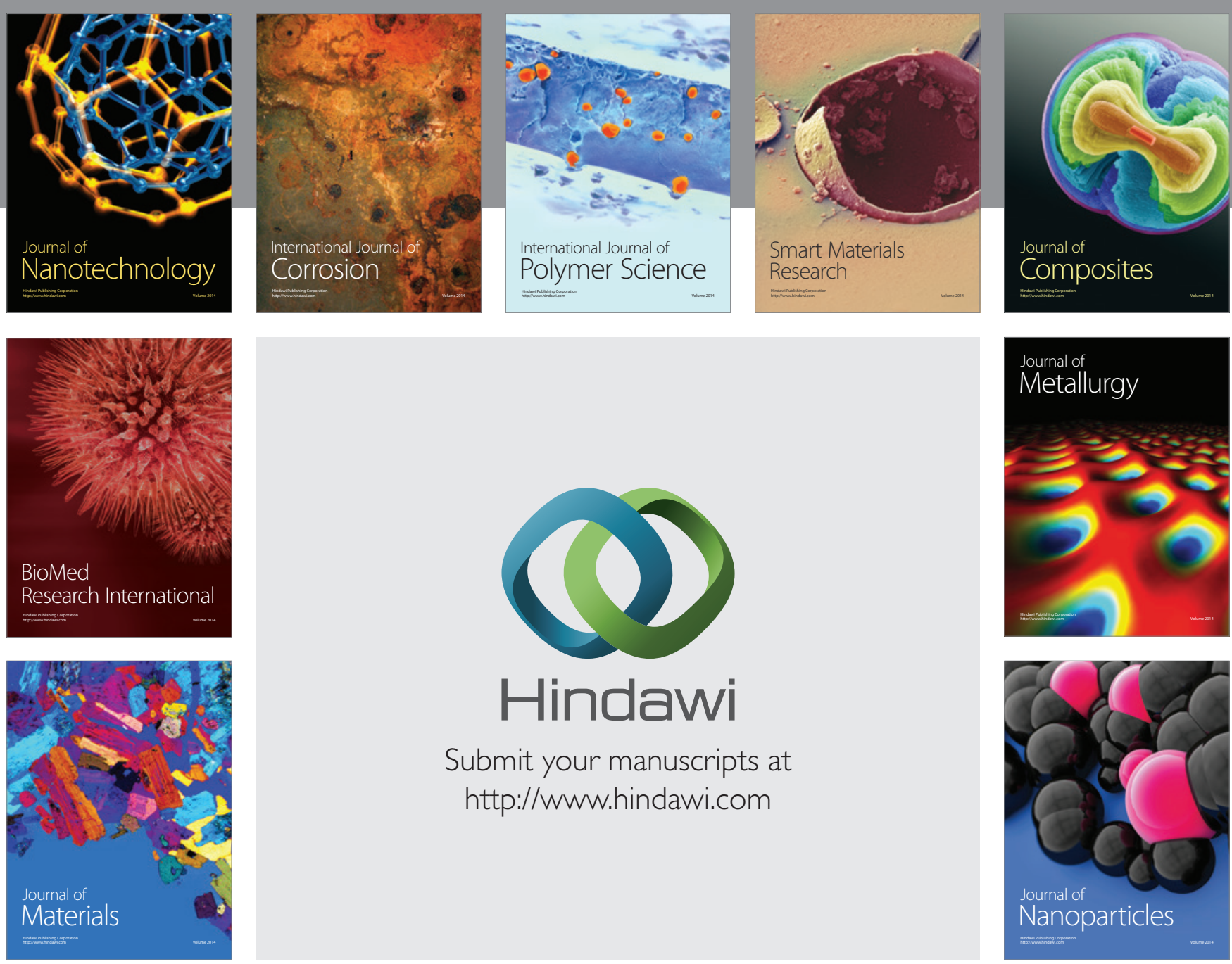

Submit your manuscripts at http://www.hindawi.com
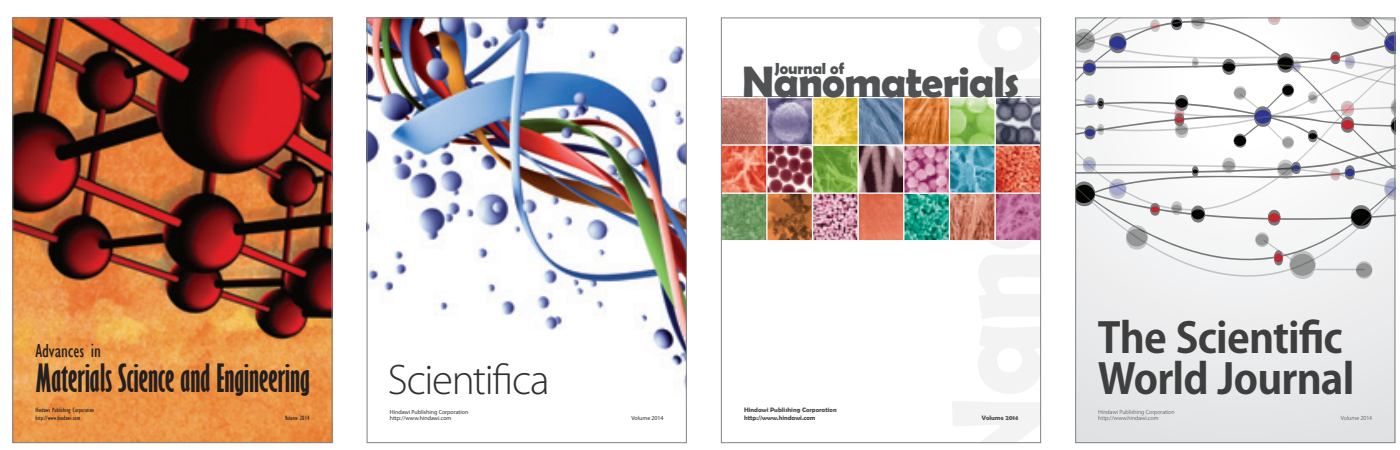

\section{The Scientific World Journal}
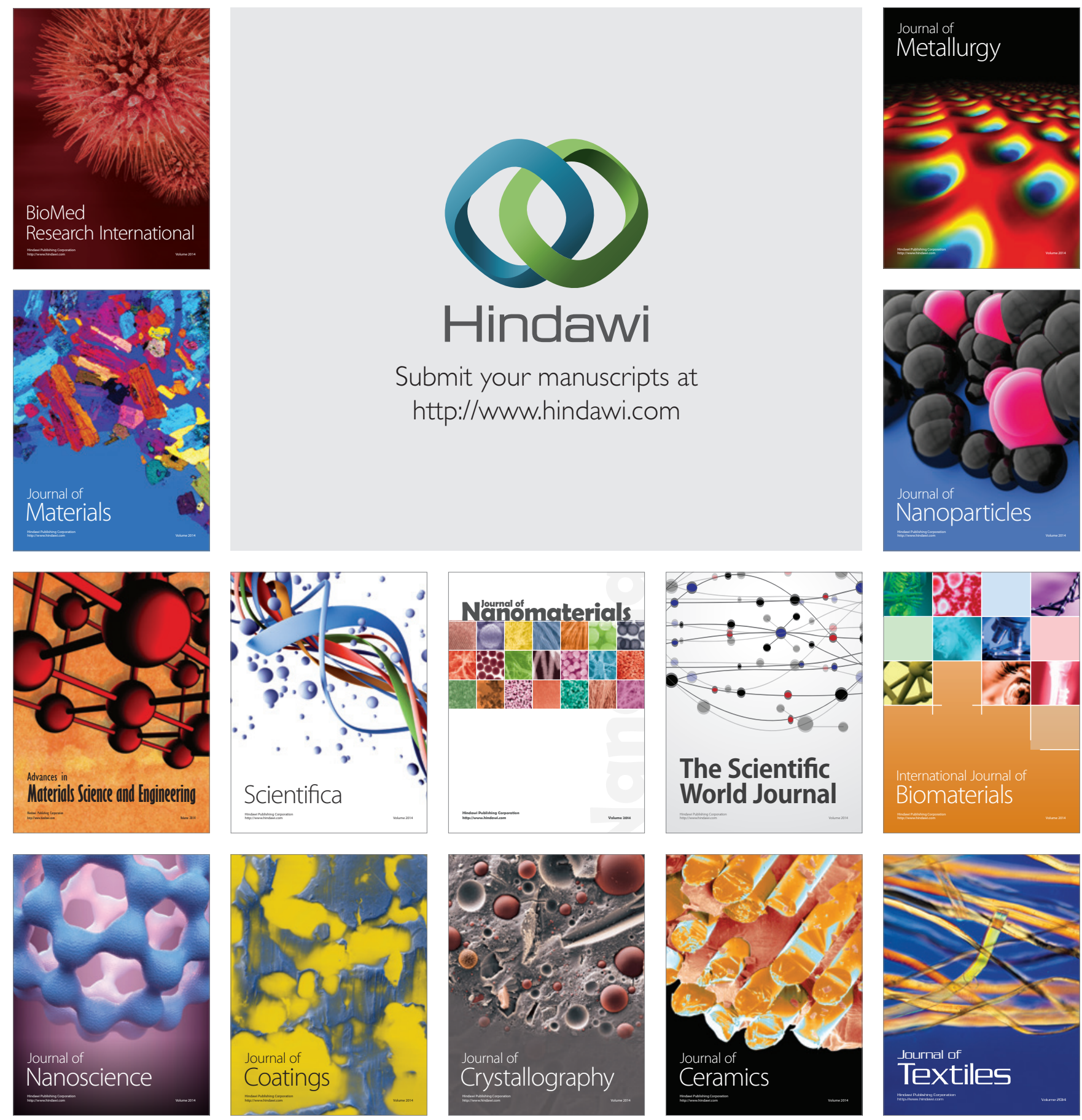